\title{
स्वाध्याय का किशोरियों की संवेगात्मक बुद्धिमत्ता पर प्रभाव का अध्ययन।
}

दीपक सिंह, गुंजन शर्मा, प्रज्ञा सिंह लोधी, सुभाष कश्यप एवं भानू प्रकाश जोशी

सारांश

प्रस्तुत शोध का मुख्य उद्देश्य स्वाध्याय का किशोरियों की संवेगात्मक बुद्धिमत्ता पर पडने वाले प्रभाव का अध्ययन करना है। स्वाध्याय आत्म उन्नति का महान साधन है। वास्तविक स्वाध्याय वही है जिससे व्यक्तिकी चिन्ताए दूर हो, शंका-कुशंकाओ का समाधान हो, मन मे सद्भाव व शुभ संकल्पो का उदय हो, तथा आत्मा को शान्ति का अनुभव हो। इस अध्ययन में प्रयोगात्मक एवं नियन्त्रित समूह अभिकल्प का प्रयोग किया गया है। अध्ययन हेतु आकस्मिक प्रतिचयन विधि द्वारा श्री राम कॉलेज मुजफ्फरनगर उ०प्र० से 16 से 18 वर्ष की 100 छात्राओं का चयन किया गया। जिनमें से 50 छात्राओं को प्रयोगात्मक समूह तथा 50 छात्राओं को नियन्त्रित समूह में रखा गया। स्वाध्याय हेतु किशोरियों को 3 माह तक सप्ताह में 5 दिन नियमित रुप से 30 मिनट तक स्वाध्याय करवाया गया। मानसिक स्वास्थ्य मापनी द्वारा आँकडों का संग्रहण किया गया। सांख्यिकीय विश्लेषण हेतु एस० पी० एस० एस० वर्जन 9 द्वारा अनोवा परीक्षण का उपयोग किया गया। अध्ययन से प्राप्त परिणामों से यह स्पष्ट होता है कि स्वाध्याय का किशोरियों की संवेगात्मक बुद्धि पर सकारात्मक प्रभाव पडता है।

कूट शब्द - संवेगात्मक बुद्धिमत्ता, स्वाध्याय, अखण्ड ज्योति, किशोरियाँ, पंचतन्त्र की कहानियाँ।

सांवेगिक बुद्धि एक प्रकार की सामाजिक बुद्धि होती है। जो कि सामान्य बुद्धि से भिन्न सम्प्रत्यय है। साथ ही साथ व्यक्ति के जीवन के विभिन्न आयामों में सांवेगिक बुद्धि महत्वपूर्ण भूमिका निभाती है। विभिन्न प्रकार के कार्यक्षेत्रों में सफल लोगो के व्यक्तित्व के अध्ययनों से यह तथ्य प्राप्त होते है कि व्यक्ति की सफलता में उसकी सामान्य बुद्धि की अपेक्षा सांवेगिक बुद्धि के तत्व जैसे आशावादिता, सांवेगिक संवेदनशीलता एवं सांवेगिक प्रबंन्धन इत्यादि महत्वपूर्ण भूमिका निभाते है। मनोवैज्ञानिकों ने सांवेगिक बुद्धि को निम्न प्रकार से परिभाषित किया है-

मॉयर एवं सैलोवी के अनुसार" संवेगात्मक बुद्धि से अभिप्राय संवेगों को प्रत्यक्षण करने की क्षमता, संवेगो के प्रति पहुँच बनाने एवं उन्हें उत्पन्न करने की क्षमता (ताकि चिन्तन में मदद हो सके), संवेग एवं संवेगात्मक ज्ञान को समझा जा सके तथा संवेगों को चिन्तन शक्ति के द्वारा ढंग से नियमित किया जा सके, (ताकि सांवेगिक एवं बौद्धिक वर्द्धन को उन्नत बनाया जा सके) से होता है (Mayer \& Salove, 2000)। गोलमैन के अनुसार 'संवेगात्मक बुद्धि अपने एवं दूसरो के भावनाओं को पहचानने की क्षेतता तथा अपने आपको अभिप्रेरित करके एवं अपने एवं अपने सबंधों में संवेगों को प्रबंधित करने की क्षमता है। संवेगात्मक बुद्धि द्वारा उन क्षमताओं का वर्णन होता है जो शैक्षिक बुद्धि या बुद्धिलब्धि द्वारा मापे जाने वाले पूर्णतः संज्ञानात्मक क्षमताओं से भिन्न परन्तु उसके पूरक होते है (Golman, 1995, p.34)। बॉर ऑन ने संवेगात्मक बुद्धि को परिभाषित करते हुए कहा है कि संवेगात्मक बुद्धि द्वारा वह क्षमता परीलक्षित होती है, जिसके माध्यम से दैनिक पर्यावरणीय चुनौतियों के साथ निपटा जाता है और जो व्यक्ति की जिन्दगी में, जिसमें पेशेवर तथा व्यक्तिगत धन्धा भी सम्मिलित है, सफलता प्राप्त करने में मदद करता है (Baron, 2003).
वाल्टन के अनुसार भावनाओं का अस्तित्व व्यक्ति के जीवन में अत्यन्त अल्प आयु से उजागर होने लगता है, और फिर ये संवेदनाएँ आजीवन व्यक्ति के जीवन को प्रभावित करती रहती है। मनोवैज्ञानिकों ने 22 बच्चों, जिनकी उम्र 8 माह से 28 माह के लगभग थी; पर अध्ययन किया। इन बच्चों की 3 माह तक वीडियो रिकॉर्डिग के माध्यम से निगरानी की गई। परिणाम में यह पाया गया कि छोटे बच्चे पर्याप्त रूप से अपनी एवं अपने समकक्ष बच्चों की भावनात्मक स्थिति देखने-समझने में सक्षम होते हैं। साथ ही साथ वे अपनी आन्तरिक भावनाओं को अभिव्यक्त करने तथा बाह्मय कारकों से उत्पन्न प्रभावों को, अपने दैहिक अभिव्यक्तियों को भाव-भंगिमाओं के माध्यम से संवाद कायम करने का प्रयास करते हैं। इस अध्ययन से अति कम उम्र में बच्चो में पाई जाने वाली भावनात्मक बुद्धि की उपस्थिति के प्रमाण प्राप्त होते हैं (Vollotton, 2008)।

मॉयर ने अपने लेख "संवेगात्मक बुद्धि मानक बुद्धि के रूप में, के अर्त्तगत संवेगात्मक रूप से बुद्धिमान व्यक्तियों के गुणों का वर्णन करते हुए विस्तार से इसके व्यवहार पर पड़ने वाले प्रभावों का वर्णन किया है। इनके अनुसार, "संवेगात्मक रूप से अधिक बुद्धिमान लोग दूसरे लोगों की अपेक्षाकृत अधिक बेहतर ढ़ंग से दूसरों की भावनाओं को पहचान कर, उनको विचारों में उपयोग करते हुए, उनके अर्थों को समझकर, भावनाओं को प्रबंधित कर लेते है। ऐसे लोगों के लिए भावनात्मक समस्याओं का समाधान करनें में संज्ञानात्मक क्षमताओं को कम प्रयुक्त करना पड़ता है। ऐसे लोग वाचिक, सामाजिक एवं अन्य बौद्धिक क्षमताओं में अन्य लोगो से बेहतर प्रदर्शन करते है। ऐसे लोग शिक्षण व परामर्श के क्षेत्र में क्लर्क व एडमिनिस्ट्रेशन के कार्यक्षेत्र की अपेक्षा अधिक बेहतर से कार्य सफलतापूर्वक प्रदर्शन करते है तथा संवेगात्मक रूप से बुद्धिमान लोग स्वयं को हानि पहुँचाने वाले नकारात्मक व्यवहार जैसे-धूम्रपान, अत्यधिक द्रव्य सेवन, औषध दुरूपयोग तथा हिंसात्मक व्यवहार को नजरअन्दाज करते है। 
भावनात्मक रूप से उच्च बौद्धिक क्षमता वाले लोग अपने घर-परिवार से अधिक संवेदनापूर्ण लगाव रखते है तथा सकारात्मक सामाजिक अन्त:क्रिया करते है। ऐसे लोग अपना जीवनयापन अभिप्रेरणात्मक लक्ष्य के अनुरूप करते है (Mayer et al., 2000)।

रोडे एवं उनके सहयोगियों द्वारा किए अध्ययन में संवेगात्मक बुद्धि तथा अकादमिक एवं करियर की सफलता में सकारात्मक सहसम्बन्धों का महत्त्वपूर्ण कारक यह है कि छात्र-छात्राओं को अपने शैक्षिक-अधिगम प्रक्रियाकाल में विभिन्न प्रकार की चुनौतियों का सामना करना पड़ता है, जिसके लिए उन्हें बहुत सी योग्यताओं-कुशलताओं की आवश्यकता होती है, इसलिए उच्च स्तरीय शैक्षिक निष्पादन के लिए संवेगात्मक प्रबन्धन, तनाव प्रबन्धन तथा चुनौतियों के प्रति सकारात्मक रवैया इत्यादि कुशलताए महत्त्वपूर्ण भूमिका निभाती हैं (Rode et al., 2007)। नेटाली एवं सहयोगियों के अनुसार छात्रों के उच्चस्तरीय शैक्षिक निष्पादन के लिए भी संवेगात्मक बुद्धि के विभिन्न पहलुओं से सम्बन्धित क्षमताएँ जैसे-भावनाओं की पहचान करना, सम्बन्धों में भावनाओं की अभिव्यक्ति की कुशलता एवं उनका प्रबन्धन इत्यादि महत्त्वपूर्ण आवश्यकताएँ है (Natalie et al., 2010)।

पैटरिड्स एवं सहयोगियों द्वारा 372 किशोर छात्रों की संवेगात्मक बुद्धि तथा शैक्षिक प्रदर्शन के मध्य सहसम्बन्धों का अध्ययन किया गया तो यह पाया गया कि, विश्वविद्यालय में अति उच्च शैक्षिक प्रदर्शन करने वाले छात्रों में अन्यों की अपेक्षा अधिक संवेगात्मक बुद्धि पाई गई; और इन छात्रों ने अर्न्तवैयक्तिक योग्यता, तनाव प्रबन्धन एवं समायोजन क्षमता की विमा पर भी सबसे कुशलतापूर्वक प्रदर्शन किया; (Petrides et al., 2006)। जॉन्सन के अनुसार संवेगात्मक बुद्धि, तथा संवेगात्मक स्वास्थ्य प्रभावी अधिगम के लिए प्राथमिक आवश्यकता है। किसी भी छात्र की सफलता के लिए सबसे जटिल तत्त्व यह होता है कि उसे कैसे सीखना है? जो छात्र आत्मजागरूक व स्वाभाविक रूप से अभिप्रेरित होते हैं, वे निश्चित रूप से वे उच्चस्तरीय शैक्षिक निष्पादन करते हैं। संवेगात्मक बुद्धि छात्रों में अन्त्वर्यक्तिक सम्बन्धों व सामाजिक सहयोग के आदान-प्रदान की क्षमताओं का विकास करती है, जिससे छात्र परिक्षा में अच्छा निष्पादन कर पाते है (Johnsan, 2008)।

पार्कर एवं उनके सहयोगियों के अनुसार संवेगात्मक बुद्धि के महत्त्व का वर्णन करते हुए मनोवैज्ञानिकों यह कहना है कि संवेगात्मक बुद्धि किशोरावस्था जैसे संक्रमण काल के समय किशोर छात्रों की अकादमिक सफलता तथा असफलता की पहचान में प्रभावी भविष्यवाणी करने में समर्थ होती हैं (Praker et al., 2004)। नैल्सन एवं लॉ के अनुसार जब छात्रों द्वारा स्कूल से कॉलेज, कॉलेज से करियर के चुनाव, तथा सम्बन्धित चुनौतियों तथा समस्याओं से सामना करना होता हैं, तो उस समय संवेगात्मक बुद्धि, उनके चुनाव तथा अवधारणाओं को प्रत्यक्ष रूप से प्रभावित करती है। इसलिए अकादमिक एवं करियर की सफलता-असफलता में संवेगात्मक बुद्धि, की प्रभावी भूमिका होती है (Nelson \& Low, 2003)। अतः किशोरावस्था में किशोरियों के भावनात्मक समायोजन एवं विकास के स्तर का किशोरियों की शैक्षिक
उपलब्धि के अलावा उनके जीवन के विभिन्न पहलुओ पर गम्भीर रूप से प्रभाव पडता है। इसलिए शोध के अन्तर्गत किशोरियों की संवेगात्मक बुद्धि पर स्वाध्याय के उपयोग के प्रभाव का अध्ययन किया गया है।

स्वाध्याय दो शब्दो से मिलकर बना है 'स्व' तथा 'अध्याय';'स्व' अर्थात् अपने आपका अध्ययन करना। अतः स्वाध्याय का अर्थ हुआ अपने आपको पढना, जानना-समझना आत्मचिन्तन करना आदि। प्रस्तुत शेध के अन्तर्गत स्वाध्याय का अर्थ श्रेष्ठ विचारो, श्रेष्ठ चरित्रो, महापुरुषो व सत्साहित्यो के अध्ययन से है, जिनके आधार पर व्यक्ति महापुरुषो की वैचारिक भावनात्मक स्थिति के परिप्रेक्ष्य में स्वयं का आकलन करता है और उस दिशा में आगे बढ़ने, ऊँचे उठने के लिए आवश्यक प्रेरणा व दिशा प्राप्त करता है। स्वाध्याय आत्म उन्नति का महान साधन है। वास्तविक स्वाध्याय वही है जिससे व्यक्तिकी चिन्ताए दूर हो, शंका-कुशंकाओ का समाधान हो, मन मे सद्भाव व शुभ संकल्यो का उदय हो, तथा आत्मा को शान्ति का अनुभव हो। सत्साहित्य को माध्यम बनाकर स्वाध्याय करना अधिक सरल है। सत्साहित्य सरलता से उपलब्ध भी हो जाता है, और रूचिकर एवं प्रेरणाप्रद भी होता है। इसलिए स्वाध्याय के लिए मुख्य रुप से सत्साहित्य को ही चुना जाता है।

आचार्य (1987) के अनुसार जिस प्रकार शरीर को नित्य स्नान कराना आवश्यक है, अन्यथा मैल जम जाएगा,बदबू निकलने लगती है, जिससे अनेक रोग उपज सकते है। ठीक उसी प्रकार से मन को स्नान कराने के लिए स्वाध्याय की आवश्यकता होती है। स्वाध्याय में प्रमाद करने से मन के ऊपर विकारो की परत जम जाती है, जिससे मनोविकार उपजते है, मानसिक रोगो का उद्भव होता है, मन की मलिनता से शरीर भी रोगी हो जाता है। स्वाध्याय की उपेक्षा करना, उसमें प्रमाद बरतना मन को रोगी बनाने के समान है (पृ0 2.6)। पण्ड्या (2014) के अनुसार- मनुष्य विचारो का पुन्ज है। अपने दृष्टिकोण के आधार प रवह अपने जीवन के बाहय और आन्तरिक स्तर को निर्मित करता है (पृ० 40)। ब्रहमवर्चस (1991) स्कूल, कॉलेजो, में पढाई जाने वाली शिक्षा, जीविकोपार्जन, एंव लोक व्यवहार में निपुणता प्राप्त करने के लिए होती है। यह आवश्यक भी हैक्योकिं इसके बिना सांसारिक जीवन में सुस्थिरता एंव उन्नति का मार्ग नही खुलता। लेकिन इससे भी आवश्यक विद्या है, जिस ज्ञान को प्राप्त कर मनुष्य उच्च मान्यताओ, आकांक्षाओ एंव आदर्शो का निर्माण करता है, इसे प्राप्त करने का माध्यम स्कूल, कॉलेज नही वरन् स्वाध्याय एंव सत्संग है। चिन्तन और मनन से, सत्साहित्य पढने से, सज्जनो के साथ रहने, उनके अभिवचन सुनने और कार्य कलाप देखने से विद्या का आविर्भाव होता है (पृ0 15.16)।

मनोवैज्ञानिकों द्वारा स्वाध्याय का पाठकों की भावनात्मकताओं ,सामाजिक सम्बन्धों तथा व्यावहारिक समस्याओं पर भी प्रभाव का अध्ययन किया गया। कम्श्चिक एवं सहयोगियों द्वारा स्वाध्याय का भावनात्मक क्षमताओं पर प्रभाव के अध्ययन में ,जर्मनी के एक विद्यालय के बाद देखभाल करने वाले केन्द्र के 7-9 वर्ष के 104 बच्चों पर अध्ययन किया गया। जिसमें छात्रों के पढने एवं पठित सामग्री के विचार-विमर्श का छात्रों की भावनात्मकता पर प्रभाव का अध्ययन किया गया। जिसमें निष्कर्ष यह 
आए कि छात्रों द्वारा जब पठित सामग्री को महसूस करने का प्रयास किया जाता है, तो इससे उनकी भावनात्मक वर्तनी, भावनात्मक ज्ञान तथा भावनाओं को समझने की क्षमता का विकास होता है। तथा यह समझ लड़कियों की अपेक्षा लड़कों में अधिक विकसित होती पाई गई (Kumschick et al., 2014) बिलिन्गटन ने नियमित रुप से पठन क्रिया में संलग्न रहने वाले 4000 युवाओं पर सर्वे विधि द्वारा एक 14 प्रश्नों वाली प्रश्नावली के प्रयोग से अध्ययन किया गया, जिसका उद्धेश्य पढ़ने का व्यक्ति के सामान्य मनोदशा, स्वस्ति भावना, सामाजिक अन्तःक्रिया से सम्बन्ध का अध्ययन करना था। परिणाम में यह पाया गया कि जो लोग स्वेच्छा से सुख प्राप्ति के लिए अध्ययन करते हैं; उनमें अपने समूह के प्रति अधिक जागरूकता, अधिक सामाजिक समावेशितता, सामाजिक अवसरों में अधिक प्रसन्नतापूर्वक भागीदारी, तथा खुलेपन की भावना व बातूनीपन में वृद्धि पाई गई (Billingtion, 2015)।

\section{प्रतिदर्श चयन विधि एवंप्रतिदर्श}

प्रस्तुत अध्ययन हेतू 'आकस्मिक प्रतिचयन विधि' द्वारा श्री राम कॉलेज मुजफ्फरनगर उ०प्र० से 100 छात्राओं का चयन किया गया। जिनमें से 50 छात्राओं को प्रयोगात्मक समूह में तथा 50 छात्राओं को नियन्त्रित समूह में सम्मिलित किया गया है।

\section{समावेशन मापदण्ड}

प्रस्तुत शोध में 16 वर्ष से 18 वर्ष तक की उन्हीं किशोरियों को सम्मिलित किया जाएगा जिनकी शैक्षणिक योग्यता कम से कम हाईस्कूल हो तथा जो शारीरिक मानसिक रूप से स्वस्थ हो।

\section{अपवर्जन मापदण्ड}

प्रस्तुत शोध में उन किशोरियों को सम्मिलित नही किया गया जो किसी प्रकार से शारीरिक व मानसिक रूप से अस्वस्थ हो या कक्षा मे अनियमित हो, अथवा शोध कार्य में सम्मिलित होने में इच्छुक नहीं हो।

\section{अनुसंधान अभिकल्प}

प्रस्तुत अध्ययन में 'प्रयोगात्मक एवं नियन्त्रित समूह अभिकल्प' का उपयोग किया गया। जिसमें शोधकर्ता ने प्रतिदर्श को दो भागो में विभाजित कर लेता है। जिनमें एक समूह को प्रयोगात्मक परिस्थिति में तथा दूसरे समूह को नियन्त्रित परिस्थिति में रख कर अध्ययन किया जाता है। अध्ययन से पूर्व व पश्चात् दोनों समूहों मे आश्रित चर का मापन कर तुलना की जाती है।

\section{प्रयुक्त परीक्षण}

संवेगात्मक बुद्धिमता के मापन हेतु डॉ० शीतला प्रसाद (2009) द्वारा निर्मित "संवेगात्मक बुद्धिमता मापनी का प्रयोग किया गया हैं। इस मापनी के अर्न्तगत कुल 40 पद सम्मिलित हैं। जो कि भावनात्मक बुद्धिमता के मापन हेतु निर्मित किए गए है। प्रस्तुत परीक्षण में संवेगात्मक बुद्धि की निम्न 5 विमाए -आत्मसंयम, विश्वसनीयता, विवेकशीलता, नवोन्मेष, तथा समायोजनशीलता सम्मिलित की गई हैं तथा निम्न 5 भावनात्मक दक्षताएँ -स्वतन्त्रता, परस्पर निर्भरता, श्रेणीबद्धता,. अति आवश्यक लेकिन अपर्याप्त, सामान्य सम्मिलित की गई हैं।

\section{कार्य विधि}

प्रस्तुत अध्ययन हेतू आकस्मिक प्रतिचयन विधि द्वारा श्री राम कॉलेज मुजफफ्फरनगर उ०प्र० से 16 से 18 वर्ष की 100 छात्राओं का चयन किया गया, जिनमें से 50 छात्राओं को प्रयोगात्मक समूह में तथा 50 छात्राओं को नियन्त्रित समूह में सम्मिलित किया गया है। शोध में सम्मिलित प्रयोगात्मक समूह की किशोरियों को स्वाध्याय का अभ्यास करवाया गया। स्वाध्याय हेतू प्रयोज्यों को अखण्ड ज्योति मासिक पत्रिकाएं तथा पंचतन्त्र की कहानियों का अध्ययन तीन माह तक 30 मिनट (सप्ताह में 5 दिन) करवाया गया। जबकि नियन्त्रित समूह की छात्राओं को किसी प्रकार का अभ्यास नही करवाया गया। संवेगात्मक बुद्धि मापनी द्वारा दोनों समूह की किशेरियों की संवेगात्मक बुद्धि का तीन चरणों - अध्ययन से पूर्व अवस्था, 45 दिनों बाद मध्य अवस्था में तथा 3 माह बाद अन्तिम अवस्था में मापन कर आँकडो का संग्रह किया गया।

\section{शून्य उपकल्पना.}

स्वाध्याय करने वाली किशोरियों एवं स्वाध्याय न करने वाली किशोरियों की संवेगात्मक बुद्धि में कोई सार्थक अन्तर नही होता है। स्वाध्याय विधि के उपयोग का किशोरियों की संवेगात्मक बुद्विमत्ता पर कोई सार्थक प्रभाव नहीं पडता है।

\section{सांख्यिकीय विश्लेषण}

प्रस्तुत शोध के परिणामो के सांख्यिकीय विश्लेषण हेतू एस पी एस एस वर्जन 18 के माध्यम से 'वन वे अनोवा' परिक्षण का उपयोग किया गया है। तथा प्रयोगात्मक एवं अप्रयोगात्मक समूहों के गेन प्राप्तांको के मध्यमान के अन्तर को ज्ञात करने के लिए टी-परिक्षण का उपयोग किया गया है। 
शोध परिणाम

शून्य परिकल्पना (1)- स्वाध्याय करने वाली किशोरियों एवं स्वाध्याय न करने वाली किशोरियों की संवेगात्मक बुद्धि में सार्थक अन्तर नहीं होता है।

\begin{tabular}{|l|l|l|l|l|l|l|l|}
\hline Group & $\mathrm{N}$ & Mean & S.D. & SE & df & t-value & Sign. \\
\hline Experimental Group & 50 & 49.41 & 7.03 & 7.13 & 98 & 9.10 & 0.01 \\
\hline Controlled Group & 50 & 1.40 & 1.18 & & & & \\
\hline
\end{tabular}

उपरोक्त सारिणी के अनुसार यह स्पष्ट होता है कि प्रयोगात्मक समूह के gain score* (पूर्व व अन्तिम परिक्षण के प्राप्तांको के अन्तर) का मध्यमान व मानक विचलन क्रमशः $49.41 \pm 7.03$ है तथा नियंत्रित समूह के gain score (पूर्व व अन्तिंम परिक्षण के प्राप्तांको के अन्तर) का मध्यमान व मानक विचलन क्रमशः $1.40 \pm 1.18$ है। मानक त्रुटि विचलन 1.04 तथा $\mathrm{t}$ का मान 8.38 है, जो कि $98 \mathrm{df}$ के साथ टी-सारणी में 0.01 स्तर पर सार्थक है। इससे यह स्पष्ट होता है कि दोनो समूहो के मध्यमानों के बीच सार्थक अन्तर है तथा शून्य परिकल्पना 'स्वाध्याय करने वाली एवं स्वाध्याय न करने वाली किशोरियों की संवेगात्मक बुद्धि में कोई अन्तर नही होता है निरस्त की जाती है। अतः शोध परिणाम सें यह स्पष्ट होता है कि स्वाध्याय का संवेगात्मक बुद्धि पर सार्थक व सकारात्मक प्रभाव पडता है।

शून्य उपकल्पना (2)- स्वाध्याय विधि के उपयोग का किशोरियों की संवेगात्मक बुद्विमत्ता पर कोई सार्थक प्रभाव नही पडता है।

Test of Within-Subjects Effects

\begin{tabular}{|l|l|l|l|l|l|l|l|} 
Source & Correction & $\begin{array}{l}\text { (Type III) } \\
\text { Squares }\end{array}$ & Sum of & df & Mean Square & F \\
\hline time & $\begin{array}{l}\text { Greenhouse- } \\
\text { Geisser }\end{array}$ & 62628.175 & 1.202 & 52121.54 & 76.82 & .00 \\
\hline $\begin{array}{l}\text { Error } \\
\text { (time) }\end{array}$ & $\begin{array}{l}\text { Greenhouse- } \\
\text { Geisser }\end{array}$ & 39944.198 & 58.87 & 678.43 & \\
\hline
\end{tabular}

Tests of Within-Subjects Effects तालिका से यह ज्ञात होता है कि प्रायोगिक समूह में स्वाध्याय करने वाली किशोरियों का विभिन्न समयान्तरालों पर संवेगात्मक बुद्धि के मध्यमानों के बीच सार्थक अन्तर $(\mathrm{F}(1.20,58.87)=76.82, \mathrm{p}<0.000)$ है।

Descriptive Statistics

\begin{tabular}{|l|l|l|l|l|}
\hline Conditions & Tests & Mean & S.D. & N \\
\hline Condition-1 & Pre-test & 85.52 & 5.75 & 50 \\
\hline Condition-2 & Mid-test & 103.348 & 15.23 & 50 \\
\hline Condition-3 & Post-test & 134.940 & 36.44 & 50 \\
\hline
\end{tabular}


Pairwise comparisons

\begin{tabular}{|l|l|l|l|l|}
\hline (I) conditions & $(\mathbf{J})$ conditions & Mean difference (I-J) & Std.Error & Sig. \\
\hline pre- test (1) & mid- test (2) & $-17.824^{*}$ & 1.901 & .000 \\
\hline pre- test (1) & post- test (3) & $-49.416^{*}$ & 5.106 & .000 \\
\hline mid- test (2) & post- test (3) & $-31.592^{*}$ & 4.385 & .000 \\
\hline
\end{tabular}

Descriptive table के अनुसार स्वाध्याय करने वाले समूह की किशोरियों की संवेगात्मक बुद्धि में स्वाध्याय आरम्भ करने से पूर्व परिक्षण (85.52 \pm 5.75$)$ कि तुलना में मध्य परिक्षण $(103.34 \pm 15.23, \mathrm{P}=0.000)$ व पश्चात परिक्षण $(134.94 \pm 36.44, \mathrm{P}=0.000)$ तथा मध्य परिक्षण $(103.34 \pm 15.23)$ कि तुलना में पश्चात परिक्षण $(134.94 \pm 36.44, P=0.000)$ के बीच साख्यिकीय रूप से सार्थक अन्तर है। Pairwise Comparisons हेतू Tukey Post Hoc Test के द्वारा गणना की गयी, जिससे प्राप्त निष्कर्षो के अनुसार स्वाध्याय के अभ्यास का समय अन्तराल के साथ किशोरियों की संवेगात्मक बुद्धि पर सकारात्मक प्रभाव पडता है।

अप्रायोगिक समूह में डायरी लेखन न करने वाली किशोरियों की संवेगात्मक बुद्धि के मध्यमानों के बीच सार्थकता अन्तर का विश्लेषण - Test of Within-Subjects Effects -

\begin{tabular}{|l|l|l|l|l|l|l|}
\hline Source & Correction & $\begin{array}{l}\text { (Type III) Sum of } \\
\text { Squares }\end{array}$ & df & $\begin{array}{l}\text { Mean } \\
\text { Square }\end{array}$ & F & Sig \\
\hline time & Greenhouse-Geisser & 376.193 & 1.41 & 265.40 & 2.75 & .088 \\
\hline $\begin{array}{l}\text { Error } \\
\text { (time) }\end{array}$ & Greenhouse-Geisser & 6684.40 & 69.45 & 96.243 & \\
\hline
\end{tabular}

Tests of Within-Subjects Effects तालिका सें यह ज्ञात होता है कि नियंत्रित समूह की किशोरियों का विभिन्न समयान्तरालों पर संवेगात्मक बुद्धि के मध्यमानों के बीच कोई सार्थक अन्तर नहीं है $(\mathrm{F}(1.41,69.45)=2.75, \mathrm{P}=.088)$ है।

\section{Descriptive Statistics}

\begin{tabular}{|l|l|l|l|l|}
\hline Conditions & Tests & Mean & S.D. & N \\
\hline Condition-1 & Pre-test & 28.600 & 5.12 & 50 \\
\hline Condition-2 & Mid-test & 29.640 & 5.18 & 50 \\
\hline Condition-3 & Post-test & 29.420 & 4.633 & 50 \\
\hline
\end{tabular}


सिंह, शर्मा, लोधी, कश्यप एवं जोशी

Pairwise comparisons

\begin{tabular}{|l|l|l|l|l|}
\hline (I) conditions & $(\mathbf{J})$ conditions & Mean difference (I-J) & Std. Error & Sig. \\
\hline pre- test $(1)$ & mid- test (2) & -3.834 & 2.114 & .228 \\
\hline pre- test (1) & post- test (3) & -1.406 & 1.310 & .865 \\
\hline mid- test (2) & post- test (3) & 2.428 & 1.414 & .277 \\
\hline
\end{tabular}

Descriptive table के अनुसार स्वाध्याय करने वाले समूह की किशोरियों की संवेगात्मक बुद्धि में अध्ययन आरम्भ करने से पूर्व परिक्षण (90.30 \pm 7.45$)$ कि तुलना में मध्य परिक्षण $(94.14 \pm 16.58, P=.22)$ व पश्चात परिक्षण (91.71 $\pm 10.51, P=.86)$ तथा मध्य परिक्षण (94.14 \pm 16.58) कि तुलना में पश्चात परिक्षण (91.71 $\pm 10.51, P=.27)$ के बीच साख्यिकीय रूप से कोई सार्थक अन्तर नहीं है। अतः यह कहा जा सकता है कि कम व अधिक दोनों समयावधियों का संवेगात्मक बुद्धि पर कोई सार्थक प्रभाव नहीं पडता है। Pairwise Comparisons हेतू Tukey Post Hoc Test के द्वारा गणना की गयी, जिससे प्राप्त निष्कर्षो के अनुसार स्वाध्याय न करने वाली किशोरियों की संवेगात्मक बुद्धि पर समय अन्तराल के साथ कोई सार्थक अन्तर नही प्राप्त हुआ।

\section{परिणामों की विवेचना}

प्रस्तुत शोध से यह निष्कर्ष प्राप्त होते है कि स्वाध्याय का किशोरियों की संवेगात्मक बुद्धि पर सकारात्मक प्रभाव पडता है। तथा स्वाध्याय करने वाली तथा स्वाध्याय न करने वाली किशोरियों की संवेगात्मक बुद्धि मे सार्थक अन्तर प्राप्त हुए। स्वाध्याय एक सरल, मनोरंजक, उत्साहजनक व ज्ञानवर्धक प्रकिया है।जिसके माध्यम से व्यक्ति को अपने आपको जानने समझने व विकसित करने का अवसर प्राप्त होता है। अध्ययनशीलता सुख-दु:ख व सम्पत्ति दोनो स्थितियों में सहायक होती है। अच्छे, उपयोगी, और ऊँची शक्तियों का विकास करने वाले साहित्य से हमारा चरित्र व भविष्य बनता है। गम्भीर साहित्य के सत्संग के बिना मनुष्य का बौद्धिक और नैतिक विकास कदापि सम्भव नही है। अच्छी पुस्तकों में अच्छे विचार होते है।

अपनी प्रसिद्ध पुस्तक "आत्मोत्कर्ष का आधार-ज्ञान" में परम पूज्य गुरुदेव ने स्वाध्याय के सन्दर्भ में निम्न प्रमुख तथ्यों पर प्रकाश डाला है:-जो मनुष्य ज्ञान प्राप्त कर लेते है, वे शील, विनम्रता, शिष्टता जैसे सद्गुणों के साथ आत्मविकास में प्रवृत्त रहते है। ज्ञान के अभाव में वह जीवन-गति की सही दिशा को न तो पहचान पाता है और न ही उसका निर्माण कर पाता है, जो व्यक्ति अपने जीवन को सफल एवं सार्थक बनाना चाहता है, उसे ज्ञानार्जन के लिए पुरुषार्थ करना ही होगा। आचार्य श्री राम शर्मा (1987) के अनुसार सद्साहित्य अपने आपमें एक विकसित मस्तिष्क होता है। जो मस्तिष्क की ताकत बढ़ाने, उसमें कल्पनाशक्ति, विचारशक्ति, सृजनशक्ति विकसित करता है। अतः किसी ऐसे विषय का अध्ययन करना चाहिए जिसमें चिन्तन तथा मनन करना पड़े, यही सही मस्तिष्कीय व्यायाम है, जो मस्तिष्कीय तन्तुओं के विकास तथा उन्हे स्वस्थ रखने में सहायक होता है।

संक्षेप में स्वाध्याय से अभिप्राय, अपने आपको पढ़ने, समझने अर्थात् स्वयं के अध्ययन-आत्मचिन्तन से है। श्रीमद्भगवद् गीता में भगवान श्री कृष्ण कहते है - स्वाध्यायाभ्यसनं चैव वांडमय तप उच्यते (गीता, 17/18) अर्थात् स्वाध्याय करना ही प्राणी का तप है। जो मनुष्य सत्पथप्रदर्शक अपने सच्चे सखा स्वाध्याय का परित्याग कर देता है, उसकी नाड़ियां-इन्द्रियां आदि उच्छृंखल हो जाती है, जिससे उसे दु:खो का भागी बनना पड़ता है, और व्यक्ति की मानसिक एकाग्रता चली जाती है। स्वाध्याय व्यक्ति के जीवन में नियम-संयम अनुशासन आदि उपयोगी आचरणों के विकास में अत्यधिक प्रभावी होता है। अतः स्वाध्याय के लिए प्रयुक्त किए गए माध्यम अखण्ड ज्योति मासिक पत्रिका तथा पन्चतन्त्र की कहानियॉ किशेरियो को उनकी भावनाओं के प्रबन्धन तथा भावनात्मक बुद्धि के विकास के लिए प्रभावी साबित हुई।

प्रस्तुत परिणाम स्वाध्याय के भावनात्मक बुद्धि पर प्रभाव के परिप्रेक्ष्य में किए गए डंकन के अध्ययन के समकक्ष है; डंकन ने स्वाध्याय तथा सामाजिक सहभागिता के अध्ययन में पाया गया कि नियमित रूप से पुस्तक या अन्य सामग्रियों का अध्ययन करने वाले पाठकों में सामाजिक सहभागिता तथा सम्बन्धों में सुधार के स्तर में भी वृद्धि पाई गई। अध्ययन में भाग लेने वाले पाठकों ने बताया कि जब उन्होंने अपनी पुस्तकें अपने दोस्तों, परिवारजनों तथा पड़ोसियों के साथ बांटी, तथा उन्हें पुस्तक पढने के लिए भी प्रोत्साहित किया और पुस्तक के जिस हिस्से को उन्होने पढा उसकी चर्चा भी की, तो इससे उन्हें सामाजिक-पारिवारिक सम्बन्धों में करीब आने का अवसर मिला तथा भिन्न-भिन्न प्रकार की सामाजिक पृष्ठभूमि की जानकारी प्राप्त कर वैश्विक स्तर पर नए आइडिया मिलने एवं 
बॉटने का अवसर भी प्राप्त हुआ (Duncan, 2010)। बार ऑन के शब्दों मे सांवेगिक बुद्धि सामाजिक बुद्धि का एक प्रकार है जिसके द्वारा व्यक्ति अपने एवं दूसरों के भाव एवं संवेगों को प्रबंधित करता है, सांवेगिक बुद्धि के कारण ही व्यक्ति जटिल परिशिथती में आत्मसंयम और अपने कर्तव्यों का सही ढंग से निर्वाह कर पाता है। (Baron, 2003) और स्वाध्याय की प्रक्रिया व्यक्ति में उचित- अनुचित, सत्य असत्य का विवेक, सामाजिक, नैतिक, व्यावहारिक ज्ञान का विकास करती है।

प्रतिदिन नियमपूर्वक सद्र्रन्थों का अध्ययन करते रहने से बुद्धि तीव्र होती है, विवेक बढ़ता है और अन्त:करण की शुद्धि होती है। इसका स्वस्थ एवं व्यवहारिक कारण यह है कि सद्ग्रन्थों के अध्ययन करते समय मन उनमें रमा रहता है और ग्रन्थ के सद्वाक्य मन पर संस्कार ड़ालते रहते है। इसका अभिप्राय यह है कि स्वाध्याय की प्रवृत्ति अध्ययनकर्ता के ज्ञान के स्तर को इतना परिपक्व बना देती है कि वह व्यक्तिगत स्तर पर मानसिक एवं भावनात्मक विकास के साथ साथ सामाजिक एवं शैक्षिक स्तर पर भी उन्नति कर सकता है। एक अध्ययन में हॉग एवं लिन ने स्वाध्याय का माता-पिता तथा उनके बच्चों के अन्त:वैयक्तिक सम्बन्धों में प्रभाव का अध्ययन किया गया। जिसमें यह पाया गया कि माता-पिता जब अपनी रुचि सें कुछ समय पुस्तक पढने में समय व्यतीत करते हैं; तो इससे उनकी माता-पिता के रूप में सकारात्मक चिन्तन तथा अभिवृत्ति पर, तथा माता-पिता एवं बच्चों के सम्बन्धों पर सकारात्मक प्रभाव पड़ता है (Hong and Lin, 2012).

सांवेगिक बुद्धि द्वारा व्यक्ति अपने एवं अन्य व्यक्तियों के संवेगों के बीच विभेदन कर पाता है और इससे प्राप्त सूचनाओं के आधार पर वह अपने चिन्तन एवं क्रियाओं को निर्देशित करता है, और स्वाध्याय की प्रक्रिया व्यक्ति को अपनी भावनाओं की पहचानने तथा प्रबन्धन हेतू पर्याप्त मार्गदर्शन प्रदान करती है, तथा साथ ही साथ सकारात्मक भावनाओं के विकास में भी सहायता प्रदान करती है। ऑस्टनफील्ड एवं स्टैण्टन के अनुसार सकारात्मक भावनाओं की उपस्थिति व्यक्तियो में ऐसी अभिप्रेरणा उत्पन्न करती है, जिसके कारण वे अपनी क्षमताओं का भरपूर उपयोग कर पाते है। तथा जो लोग अपनी भावनाओं व भावनात्मक अनुभवों के आधार पर अपने जीवन में आने वाली समस्याओं के समाधान हेतु भावनात्मक प्रबन्धन की कुशलताओं को अर्जित कर, उनका समस्या समाधान में उपयोग करते हैं, वे अपने जीवन में अपेक्षाकृत अधिक सफल एवं प्रसन्न रहते है (Austenfeld \& Stanton, 2008)। मैक कैन एवं सहयोगियों के अनुसार अधिकांश मनोवैज्ञानिक इस तथ्य से सहमत है कि, अच्छे शैक्षणिक परिणाम प्राप्त करने के लिए संवेगात्मक प्रबन्धन तथा समस्या-समाधान एवं समायोजन युक्तियों की क्षमताओं का होना लाभदायक सिद्ध होता है (Mac et al., 2003) सांवेगिक बुद्धि में व्यक्ति न केवल अपने एवं दूसरे के संवेगों की पहचान करता है, बल्कि साथ ही साथ उन संवेगों के साथ तर्कणा करता है, उन्हें समझता है तथा उनका प्रबंधन भी करता है, तथा स्वाध्याय की प्रकिया सम्मिलित रूप से संवेगात्मक एवं ज्ञानात्मक पक्ष के विकास का मार्ग प्रशस्त करती है।
मोर एवं उनके सहयोगियों ने स्वाध्याय तथा सामाजिक योग्यताओं में सहसम्बन्ध के अध्ययन में स्नातक स्तर के 34 छात्रों पर अध्ययन किया गया। मिश्र-विधी डिजाइन के उपयोग से अध्ययनकर्ता ने यह पाया कि उपन्यास एवं कहानियाँ पढने की क्रिया, सामाजिक योग्यता तथा सहानुभूति की क्षमता के सन्दर्भ में प्रभावी भविष्यवाणी कर सकती है; तथा कहानी व उपन्यास के चरित्रों को व्याख्यांत्मक ढंग से समझने पर व्यक्ति वास्तविक जीवन में भी रिश्तों को एवं भावनाओं को समझने की योग्यता विकसित कर सकता है; (Mar et al., 2006)। क्लार्क एवं रनहोल्ड ने स्वाध्याय का अभिप्रेरणा के साथ सहसम्बन्ध के अध्ययन में बच्चो एवं युवाओं की अध्ययन करने की प्रवृत्ति तथा अध्ययन की प्रभावशीलता पर आन्तरिक अभिप्रेरणा की भूमिका, बाह्य प्रेरक तत्वों की प्रभावशीलता से अधिक महत्त्वपूर्ण पाई गई। अध्ययन में यह भी पाया गया कि आत्म अभिप्रेरित पठन क्रिया का, सुख की अनुभूति, सामान्यज्ञान के विकास, अन्य संस्कृतियों की समझ में वृद्धि, सामूहिक सहभागिता ,मानव प्रकृति की अन्त:दृष्टि तथा निर्णय-क्षमता से सकारात्मक रूप से सहसम्बन्ध होता है (Clark \& Runhold, 2006)।

सांवेगिक बुद्धि के सिद्धान्त के प्रतिपादक बार ने अपने सिद्धान्त के अन्तर्गत यह उपकल्पना निर्मित की कि जिन लोगो में उच्च स्तरीय संवेगात्मक बुद्धि पाई जाती है, वे अपने वातावरण की माँगो तथा दबावों का अधिक सफलतापूर्वक सामना करते है तथा जिन लोगों में संवेगात्मक बुद्धि की कमीं पाई जाती है, उनके जीवन मे भावनात्मक समस्याएं तथा असफलता की दर अपेक्षाकृत अधिक पाई जाती है तथा जिन लोगों में तनाव झेलनें की योग्यता में, समस्या-समाधान की योग्यता में, वास्तविकता की जाँच करने की योग्यता में तथा आवेग नियन्त्रण की योग्यता में कमी होती है उनको अपने वातावरण की माँगो को पूरा करने में तथा परिवर्तनशील परिसिथियों के साथ समायोजन करने में कठिनता का सामना करना पडता है (Baron, 2001)। संवेगात्मक बुद्धि तथा संज्ञानात्मक बुद्धि व्यक्ति को सामान्य बुद्धि के समान ही प्रभावित करती है और इसके आधार पर व्यक्ति के जीवन में सफलता का स्तर निर्धारित होता है, तथा स्वाध्याय की प्रक्रिया से अध्ययनकर्ता के संवेगात्मक, संज्ञानात्मक एवं मूल्यात्मक पक्ष पर सकारात्मक प्रभाव पड़ता है, जिससे अध्ययनकर्ता का मानसिक, संवेगात्मक, व्यक्तिगत, संज्ञानात्मक विकास होता है।

अतः स्पष्ट है कि स्वाध्याय से अभिप्राय, अपने आपको पढ़ने, समझने अर्थात् स्वयं के अध्ययन-आत्मचिन्तन से है। श्रीमद्भगवद् गीता में भगवान श्री कृष्ण कहते है:-स्वाध्यायाभ्यसनं चैव वांडमय तप उच्यते (गीता, $17 / 18)$ अर्थात् स्वाध्याय करना ही प्राणी का तप है। जो मनुष्य सत्पथप्रदर्शक अपने सच्चे सखा स्वाध्याय का परित्याग कर देता है, उसकी नाड़ियां-इन्द्रियां आदि उच्छृंखल हो जाती है, जिससे उसे दु:खो का भागी बनना पड़ता है, और व्यक्ति की मानसिक एकाग्रता चली जाती है। स्वाध्याय व्यक्ति के जीवन में नियम-संयम अनुशासन आदि उपयोगी आचरणों के विकास में अत्यधिक प्रभावी होता है। 


\section{निष्कर्ष}

शोध परिणामों से यह स्पष्ट होता है कि स्वाध्याय का किशोरियों की संवेगात्मक बुद्धि पर सकारात्मक प्रभाव पडता है। इस प्रकार यह कहा जा सकता है कि यदि स्वाध्याय का नियमित रूप से अभ्यास किया जाए तो किशोरियों के लिए संवेगात्मक प्रबंन्धन एवं विकास के साथ-साथ स्वाध्याय से प्राप्त होने वाले अन्य लाभों को भी प्राप्त किया जा सकता है। मनोवैज्ञानिकों ने अपने विभिन्न प्रकार के अध्ययनों से इस तथ्य के पक्ष में साक्ष्य प्रदान किए हैं कि स्वाध्याय की प्रक्रिया अध्ययनकर्ता को विषयवस्तु की समझ के विकास, संवेगात्मक, सामाजिक, सांस्कृतिक, राजनीतिक, व्यावसायिक, शैक्षिक, एवं व्यक्तित्व के विभिन्न पहलुओं के प्रति एक दृष्टिकोण एवं ज्ञान को विकसित करने में सहायता प्रदान करती है।

दीपक सिंह, पी0 एच० डी०, असिस्टेंट प्रोफेसर, मनोविज्ञान विभाग गुरूकुल कांगरी विश्वविद्यालय, हरिद्वार। गुंजन शर्मा, शोधार्थी; प्रज्ञा सिंह लोधी, पी० एच० डी०, असिस्टेंट प्रोफेसर; सुभाष कश्यप, पी० एच० डी०, असिस्टेंट प्रोफेसर, मनोविज्ञान विभाग, देव संस्कृति विश्वविद्यालय, हरिद्वार; भानू प्रकाश जोशी, पी० एच० डी०, असिस्टेंट प्रोफेसर, योग विभाग, उत्तराखण्ड मुक्त विश्वविद्यालय, हल्दवानी, नैनीताल, उत्तराखण्ड, भारत।

\section{संदर्भ सूची}

पण्ड्या, प्रणव ( नवम्बर, 2014). सदा सकारात्मक रखे सोच। अखण्ड ज्योति, 11,40 । मथुरा अखण्ड ज्योति संस्थान।

ब्रहमवर्चस (1991). शिक्षा और विद्या का सार्थक समन्वित स्वरुप/ शान्तिकुन्ज- हरिद्वार।

आचार्य, प० श्री राम शर्मा (1987). आत्मोत्कर्ष का आधार ज्ञान-अच्छी पुस्तके सच्चे मित्र| शान्तिकुन्ज- हरिद्धार।

Austenfeld, J. I. \& Stanton, A. L. (2008). Writing about emotions verses goals: effect on hostility and medical care utilization moderated by emotional approach coping process. British Journal of Health Psychology, 13, 35-38.

Baron, R. (2001). Emotional intelligence and self-actualization. In Joseph Ciarrochi, Joe Forgas, and John D. Mayer (Eds.), Emotional intelligence in everyday life: A scientific inquiry. New York: Psychology Press.

Baron, R. (2003). How important is it to educate people to be emotionally and socially intelligent, and can it be done? Perspectives in Education, 21 (4), 3-13.
Billington, J. (2015). Reading between the Lines: the Benefits of Reading for Pleasure. London : University of Liverpool.

Clark, C., \& Rumbold, K. (2006). Reading For Pleasure A Research Overview. London: The National Literacy Trust.

Duncan B. L., Miller S. D., Wampold B. E., \& Hubble M. A. (2010). The heart and soul of change. Delivering what works in therapy. Washington, DC: American Psychological Association.

Goleman, D. (1995). Emotional intelligence. New York: Bantam Books.

Hong, Z. R., \& Lin, H. S. (2012). Impacts of a Book Reading Club Intervention on Enhancing Parents' Positive Thinking. Journal of Health Psychology, 17(2), 273-284.

Johnson, G. D. K. (2008). Learning Styles and Emotional Intelligence of the Adult Learner. $\mathrm{PhD}$ dissertation, Auburn University Alabama. Retrieved from http://etd.auburn.edu/etd/bitstream/handle/10415/1066/Johnso n Gia 27.pdf.

Kumschick, I. R., Beck, L., Eid, M., Witte, G., Klann-Delius, G., Heuser, I., Steinlein, R. \& Menninghaus, W. (2014). Reading and Feeling: the effects of a literature-based intervention designed to increase emotional competence in second and third graders. Frontiers in Psychology, 5. doi: 10.3389/fpsyg.2014.01448

MacCann, C., Matthews , G., Zeidner, M. \& Roberts, R. D. (2003). Psychological Assessment of Emotional Intelligence: A Review of Self-Report and Performance-Based Testing. The International Journal of Organisational Analysis, 11,247-74.

Mar, R. A., DeYoung, C. G., Higgins, D. M. \& Peterson, J. B. (2006). Self-Liking and Self-Competence Separate SelfEvaluation From Self-Deception: Associations With Personality, Ability, and Achievement. Journal of Personality, 74(4), 10471078

Mayer, J. D., Salovey P. \& Caruso, D. (2000). Models of emotional intelligence. In R. J. Sternberg (Ed.). The Handbook of Intelligence (pp. 393-420). New York: Cambridge University Press 
Natalie, L. Shipley, M. J. J., Sharon L. S. (2010). The effects of emotional intelligence, age, work experience, and academic performance: Research in Higher Education Journal. http://www.aabri.com/manuscripts/10535.pdf

Nelson, D. \& Low, G. (2003). Emotional intelligence: achieving academic and career excellence. New Jersey : Prantic- Hall

Petrides, K. V. \& Furnham, A. (2006). The Role of Trait Emotional Intelligence in a Gender-Specific Model of Organizational Variables. Journal of Applied Social Psychology, 36, 552-69.
Parker, J. D. A., Summerfeldt, L. J., Hogan, M. J. \& Majkski, S. A. (2004). Emotional Intelligence and Academic Success: Examining the Transition from High School to University. Personality and Individual Differences, 36, 163-17.

Rode, J., Mooney, C., Arthaud-Day, M., Near, J., Baldwin, T., Rubin, R. \& Bommer, W. (2007). Emotional intelligence and individual performance: Evidence of direct and moderated effects. Journal of Organizational Behavior, 28, 399-421.

Vallotton, C. D. (2008). Signs of emotion: What can preverbal children "say" about internal states. Infant Mental Health, 29(3), 234-258. 